\title{
Electrochemical Impedance Spectroscopy Investigation of the Anodic Functionalities and Processes in LSCM-CGO-Ni Systems
}

\author{
Samir Boulfrad $^{\mathrm{a}}$, Aziz Nechache ${ }^{\mathrm{a}}$, Mark Cassidy ${ }^{\mathrm{b}}$, Enrico Traversa $^{\mathrm{a}}$, John T. S. Irvine ${ }^{\mathrm{b}}$ \\ ${ }^{a}$ Division of Physical Sciences and Engineering, King Abdullah University of \\ Science and Technology-KAUST, Saudi Arabia \\ ${ }^{\mathrm{b}}$ School of Chemistry, University of St. Andrews, Scotland, UK
}

\begin{abstract}
Electrochemical impedance spectroscopy was used to characterize anode compositions made of $\left(\mathrm{La}_{0.75} \mathrm{Sr}_{0.25}\right)_{0.97} \mathrm{Cr}_{0.5} \mathrm{Mn}_{0.5} \mathrm{O}_{3}$ (LSCM) and gadolinia doped ceria ( $\mathrm{CGO})$ with and without additional submicron $\mathrm{Ni}$, or exsoluted $\mathrm{Ni}$ nanoparticles. In addition, the effects of the anode gas flow rate and the working temperature were investigated. Higher content of the ionic conductor leads to a decrease of the impedance in the frequency range from $100 \mathrm{~Hz}$ to $10 \mathrm{~Hz}$. The effect of the catalyst component was investigated while keeping the electronic conductivity unchanged in the tested materials. Enhanced catalytic activity was demonstrated to considerably decrease the impedance especially in the frequency range between $100 \mathrm{~Hz}$ to $1 \mathrm{~Hz}$. The change in the gas flow rate affects mainly the impedance bellow $1 \mathrm{~Hz}$.
\end{abstract}

\section{Introduction}

Full ceramic anodes have been developed over the last decade as an alternative to the state-of-the-art Ni/YSZ cermet for solid oxide fuel cells. The objective is to overcome the technical limitations of the cermet, especially in high fuel utilization operational mode, when hydrocarbon fuels are used, or in systems where rapid heat up is required. Numerous oxide compositions were proposed and investigated, and the most promising are: double perovskite anode materials, strontium-titanate based perovskites and lanthanum-chromate based perovskites. $\mathrm{Sr}_{2} \mathrm{Mg}_{1-\mathrm{x}} \mathrm{Mn}_{\mathrm{x}} \mathrm{O}_{6-\delta}$ (SMMO) based double perovskite materials present good tolerance to sulfur and carbon deposition. In addition, their electronic conductivity is relatively good at intermediate temperatures (1). Strontium-titanate based perovskites have been extensively investigated because of their high potential. The properties of this material can be largely manipulated by doping A and B sites of the perovskite (2). It was also demonstrated that some of the B site dopants (for instance $\mathrm{Ni}$ and $\mathrm{Fe}$ ) can exsolve under reducing conditions in the form of nanoparticles on the top of the perovskite larger particles (3), leading to very interesting enhancement of the electrochemical performance (4).

( $\mathrm{La}, \mathrm{Sr}) \mathrm{Cr}_{0.5} \mathrm{Mn}_{0.5} \mathrm{O}_{3}$ (LSCM) perovskite has been reported as a high potential anode material because of its high tolerance to carbon and sulfur, and its redox and thermal cycling stability (5). However, similarly to other oxide anode materials, its overall performance still needs further improvement to match that of $\mathrm{Ni} / \mathrm{YSZ}$. The relatively low performance of LSCM, compared to $\mathrm{Ni} / \mathrm{YSZ}$, used to be attributed to its relatively low electronic conductivity. Recently, we have reported that pre-coating LSCM with Ni 
nitrate results in a considerable decrease in the anodic polarization resistance and activation energy (6). Ni dissolves in the perovskite phase at high temperature under oxidizing atmosphere, and then exsolves in the form of nanoparticles under reducing atmospheres (7).

This type of anode composition with split functionalities (ionic conduction, electronic conduction, and catalytic activity) gives a unique opportunity to investigate the specific influence of each of the above functions on the anodic mechanisms and performance. In this work, electrochemical impedance spectroscopy was used to characterize anode compositions containing LSCM and gadolinia doped ceria (CGO) with and without additional submicron $\mathrm{Ni}$, as well as $\mathrm{Ni}$ nanoparticles exsoluted from pre-coated larger LSCM particles. Impedance measurements were performed in a three electrode - half cell configuration from 700 to $900^{\circ} \mathrm{C}$ under two flow rates of $3 \%$ wet $\mathrm{H}_{2}$ (50 and 150 $\mathrm{mL} / \mathrm{min}$ ). The influence of CGO addition, Ni nano vs submicronic particles, the anode gas flow rate and the working temperature are presented and discussed.

\section{Experimental Procedure}

Commercial powders of LSCM, CGO and $\mathrm{NiO}$ were mixed in order to prepare the following working electrode (anode) compositions: LSCM, $85 \mathrm{wt} \% \mathrm{LSCM}+15 \mathrm{wt} \%$ CGO, $80 \mathrm{wt} \% \mathrm{LSCM}+15 \mathrm{wt} \% \mathrm{CGO}+5 \mathrm{wt} \% \mathrm{Ni}$. These will be presented through the paper as: LSCM, LSCM-15CGO and LSCM-15CGO-5Ni. The composition containing 5 $\mathrm{wt} \%$ of $\mathrm{Ni}$ was also obtained by pre-coating LSCM-CGO mixture with nickel nitrate as described in a previous publication (6), and will be presented as LSCM(5Ni)-15CGO. The counter electrode (cathode) selected was $\left(\mathrm{La}_{0.8} \mathrm{Sr}_{0.2}\right)_{0.95} \mathrm{MnO}_{3}$ (LSM). A composite of $\mathrm{Pd} / \mathrm{LSCM}$ (with 72 vol\% Pd) was used as anodic current collector. All the above electrode compositions were used to prepare screen printable inks through mixing with appropriate organic solvent, dispersant and binder.

Dense 8 YSZ pellets, with $20 \mathrm{~mm}$ diameter and $2 \mathrm{~mm}$ thickness, were prepared by uniaxially pressing powders from Pi-Kem in a $25 \mathrm{~mm}$ diameter die followed by a sintering process at $1500^{\circ} \mathrm{C}$ for $3 \mathrm{~h}$.

All samples were prepared by screen printing the above inks onto YSZ pellets. The working electrode inks were fired at $1350^{\circ} \mathrm{C}$ for 1 hour, while the counter electrode was fired at $1100^{\circ} \mathrm{C}$ for $1 \mathrm{~h}$. The samples were prepared in a half cell - three electrodes configuration as in (8).

Electrochemical impedance spectroscopy (EIS) was used to characterize the electrochemical performance and behavior of the above four working electrodes, as a function of electrode composition, temperature, and $\mathrm{H}_{2}$ electrode gas flow rate. The impedance measurements of the electrochemical half cells were performed using a Solartron 1287-1255 combination at open circuit voltage (OCV) with $20 \mathrm{mV}$ ac signal amplitude in the frequency range between $10^{4}$ to $10^{-2} \mathrm{~Hz}$, with 10 points per decade, from $700^{\circ} \mathrm{C}$ to $900^{\circ} \mathrm{C}$ under pure $\mathrm{H}_{2}$ humidified with $3 \% \mathrm{H}_{2} \mathrm{O}$. The $\mathrm{H}_{2}$ flow rate used was 50 and $150 \mathrm{~mL} / \mathrm{min}$. 


\section{Results and Discussion}

\section{Microstructure and Morphology}

Precoating LSCM powders with Ni nitrate and sintering it at high enough temperature lead to the incorporation of the nickel, up to its solid state solubility limit, into the perovskite crystals (7). As shown in Figure 1, the incorporated Ni exsolutes in the form of nano-sized particles, upon reduction in hydrogen containing atmosphere at fuel cells working temperatures.
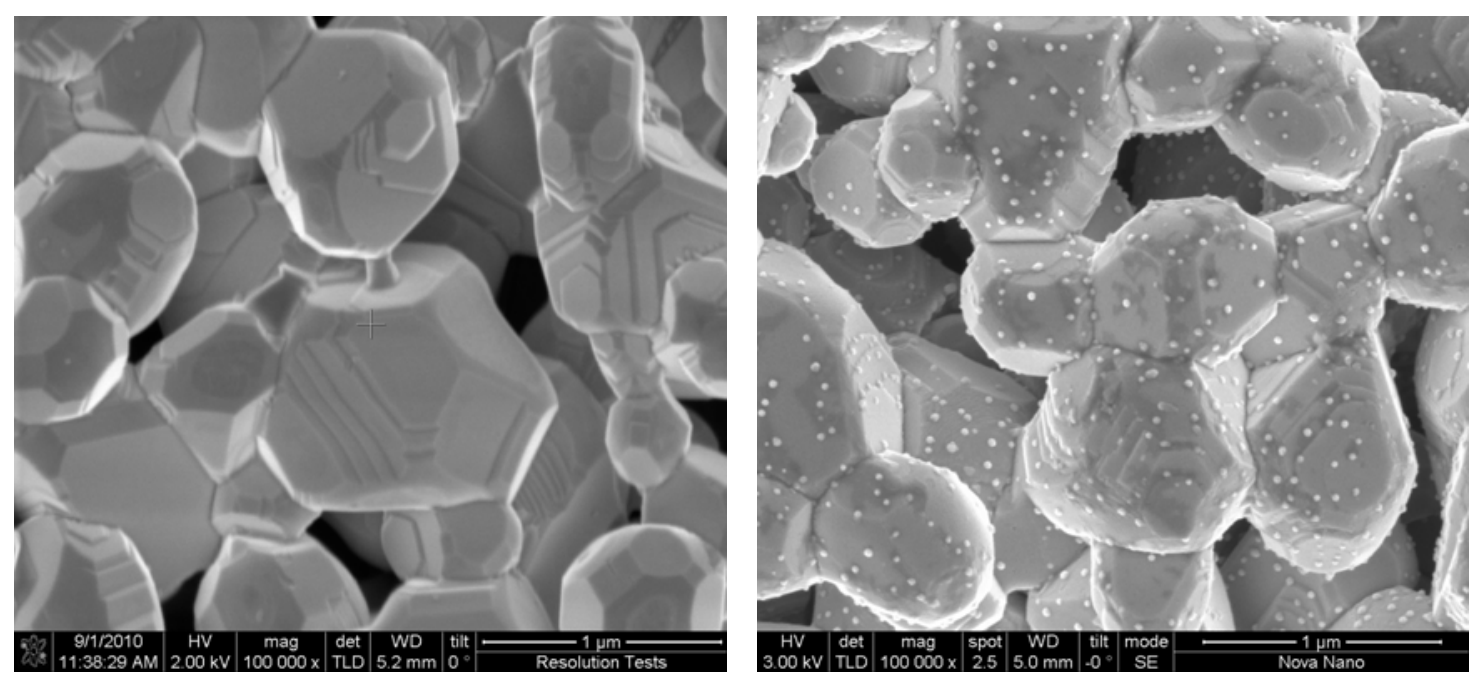

Figure 1. SEM micrographs of $\operatorname{LSCM}(5 \mathrm{Ni})-15 \mathrm{CGO}$; (left) after sintering in air at $1350^{\circ} \mathrm{C}$, (right) after post sintering reduction for $20 \mathrm{~h}$ under $5 \% \mathrm{H}_{2}$ at $900^{\circ} \mathrm{C}$.

\section{EIS Characterization}

It should be first noted that the following discussion does not consider the behavior of the ohmic resistance $R_{\Omega}$. Stability of the measurements was however ensured. Hence, the impedance diagrams shown here were presented as needed for convenience of the discussion without systematic respect of the $\mathrm{R}_{\Omega}$ values. The numbers on the impedance diagrams correspond to the logarithm of the ac measuring frequency.

Effect of the Anode Composition on the EIS Response. The influence of adding 15 $\mathrm{wt} \% \mathrm{CGO}$ and $5 \mathrm{wt} \% \mathrm{Ni}$ to the LSCM based electrode composition was investigated. As shown in Figure 2, the addition of CGO is characterized by a decrease of the impedance, especially from $100 \mathrm{~Hz}$ to $10 \mathrm{~Hz}$, leading to a slight decrease of $\mathrm{R}_{\mathrm{p}}$ value from $0.49 \Omega$ to $0.46 \Omega$, i.e. $6 \%$. This suggests that the addition of $15 \mathrm{wt} \% \mathrm{CGO}$ to the electrode composition slightly enhances the ionic conductivity of this material. Indeed, one cannot expect a considerable increase of the ionic conductivity since the amount of CGO added is not enough to form a three dimensional percolating network.

The sample LSCM(5Ni)-15CGO, showing Ni exsoluted nanoparticles, demonstrates a very significant decrease of the whole impedance diagram with an $\mathrm{R}_{\mathrm{p}}$ value of $0.26 \Omega$, i.e. a $43 \%$ decrease compared to the $\mathrm{R}_{\mathrm{p}}$ of the LSCM-15CGO sample (Figure 2). In this case, the addition of $\mathrm{Ni}$ leads to an important enhancement of all the main electrochemical mechanisms related to the $\mathrm{H}_{2}$ oxidation reaction. 


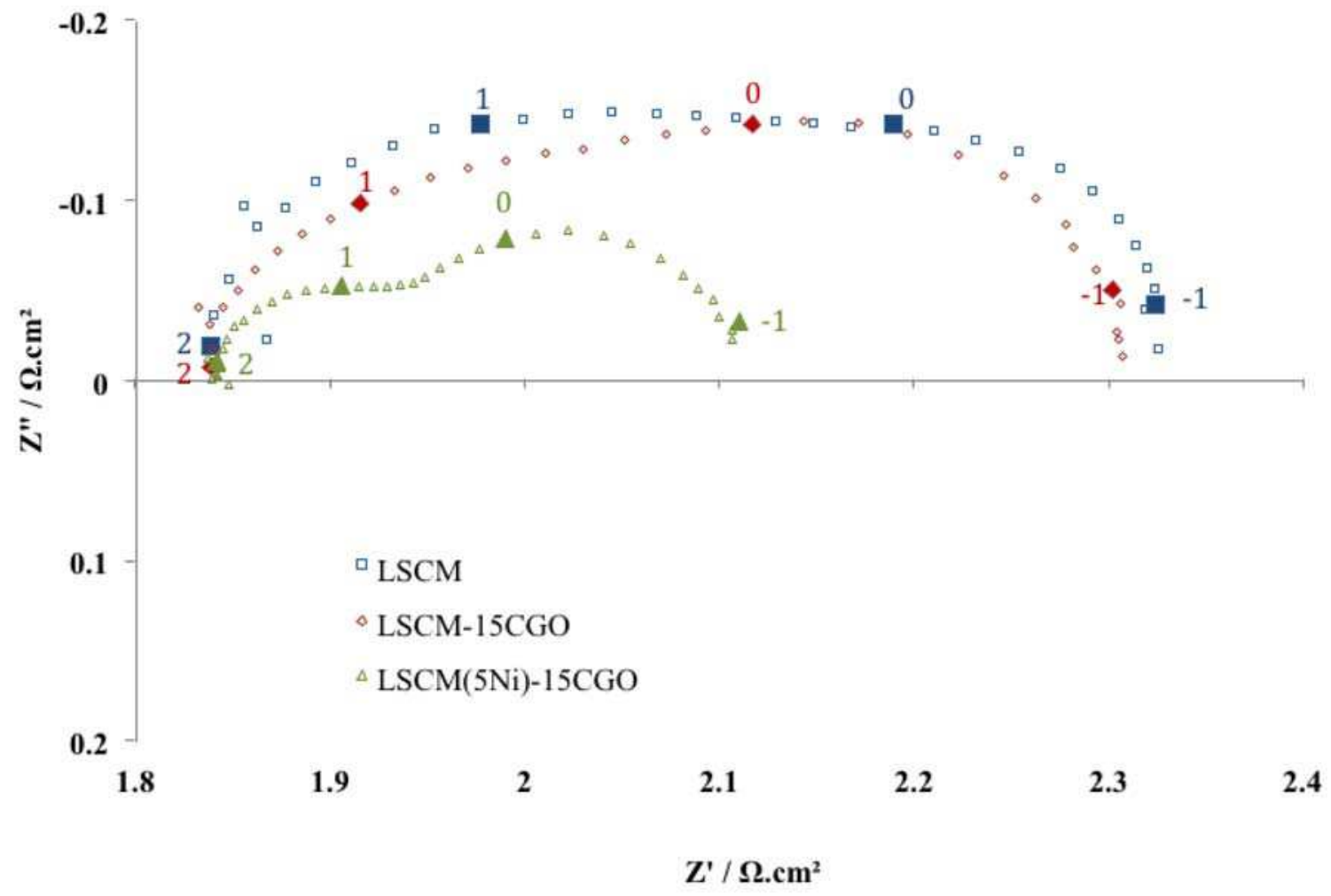

Figure 2. Impedance diagrams recorded at open circuit voltage for LSCM ( $\square$ ), LSCM$15 \mathrm{CGO}(\diamond)$ and $\operatorname{LSCM}(5 \mathrm{Ni})-15 \mathrm{CGO}(\Delta)$ material compositions. $\mathrm{T}=900^{\circ} \mathrm{C}$, anode gas composed of $97 \% \mathrm{H}_{2}+3 \% \mathrm{H}_{2} \mathrm{O}$ with a flow rate of $150 \mathrm{~mL} / \mathrm{min}$.

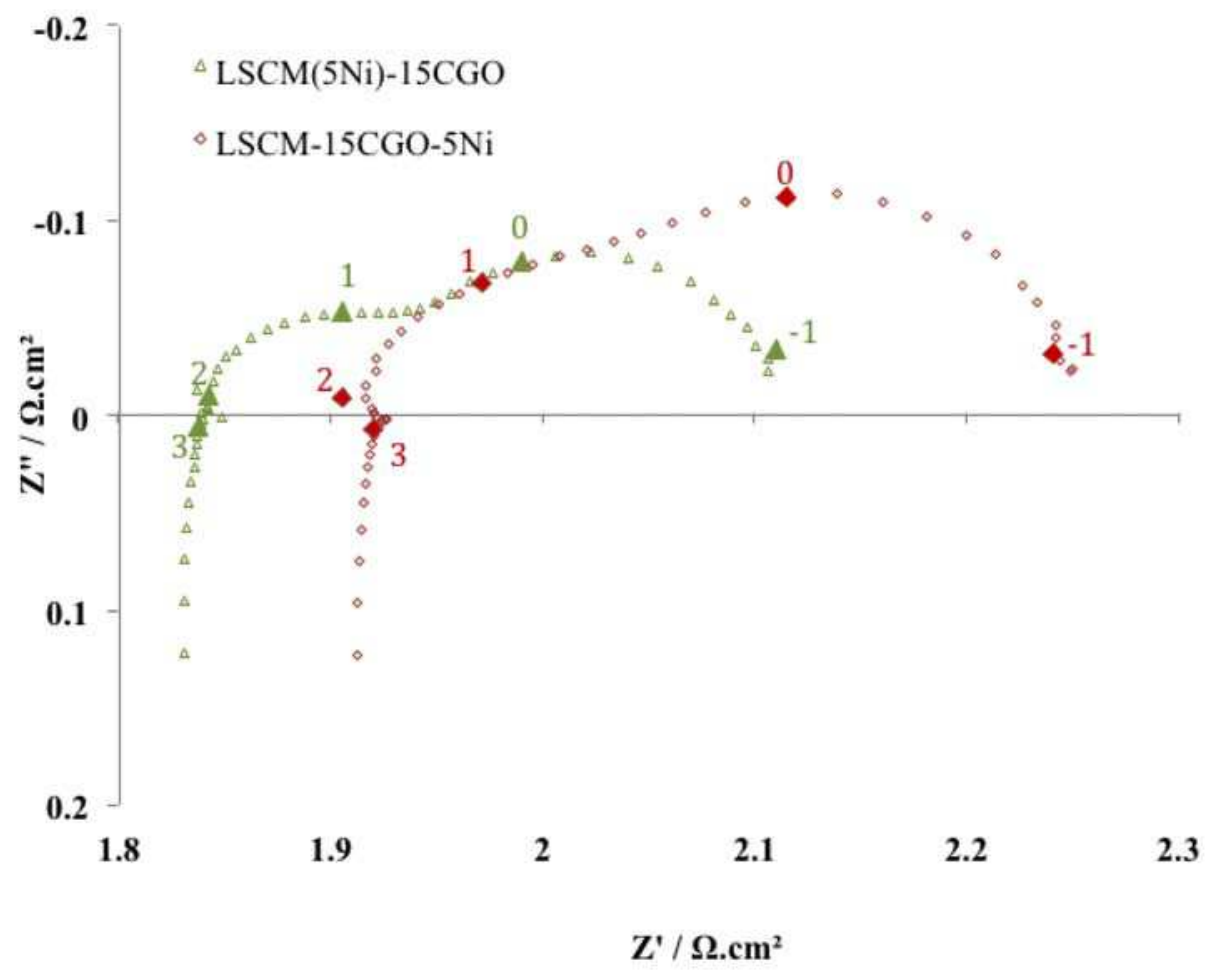

Figure 3. Impedance diagrams recorded at open circuit voltage for $\operatorname{LSCM}(5 \mathrm{Ni})-15 \mathrm{CGO}$ $(\Delta)$ and LSCM-15CGO-5Ni $(\diamond)$ material compositions. $\mathrm{T}=900^{\circ} \mathrm{C}$, anode gas composed of $97 \% \mathrm{H}_{2}+3 \% \mathrm{H}_{2} \mathrm{O}$ with a flow rate of $150 \mathrm{~mL} / \mathrm{min}$. 
The LSCM(5Ni)-15CGO and LSCM-15CGO-5Ni samples were comparatively investigated. These samples have the same amount of $\mathrm{Ni}(5 \mathrm{wt} \%)$, the first one in the form of exsoluted nanoparticles, while in the second one Ni comes from the reduction of submicronic $\mathrm{NiO}$ particles. According to Figure 3, the material containing $\mathrm{Ni}$ nanoparticles shows lower impedance than the one with submicronic $\mathrm{Ni}$, mainly with a decrease in the frequency range $[100 \mathrm{~Hz}-1 \mathrm{~Hz}]$, which includes charge transfer phenomenon at the anode triple-phase boundaries, otherwise observed between $1000 \mathrm{~Hz}$ and $100 \mathrm{~Hz}$, but under electrical load $(9,10)$. $\mathrm{R}_{\mathrm{p}}$ value decreases from $0.33 \Omega$ to $0.26 \Omega$, i.e. $21 \%$. This can be explained by the fact that Ni exsoluted nanoparticles present a more important active area than the submicronic ones, which leads to a better catalytic activity for the $\mathrm{H}_{2}$ oxidation reaction.

Effect of the Anode Gas Flow Rate on the EIS Response. As shown in Figure 4, increasing the gas flow rate from $50 \mathrm{~mL} / \mathrm{min}$ to $150 \mathrm{~mL} / \mathrm{min}$ results mainly in an important decrease in the impedance from $1 \mathrm{~Hz}$ to $0.01 \mathrm{~Hz}$, a frequency range usually associated to gas diffusion phenomena (refs). However, no differences in the EIS plots are noticed above $10 \mathrm{~Hz}$, meaning that the high-frequency part of the impedance diagram, which is related to anode charge transfer, is not sensitive to gas flow rate change.

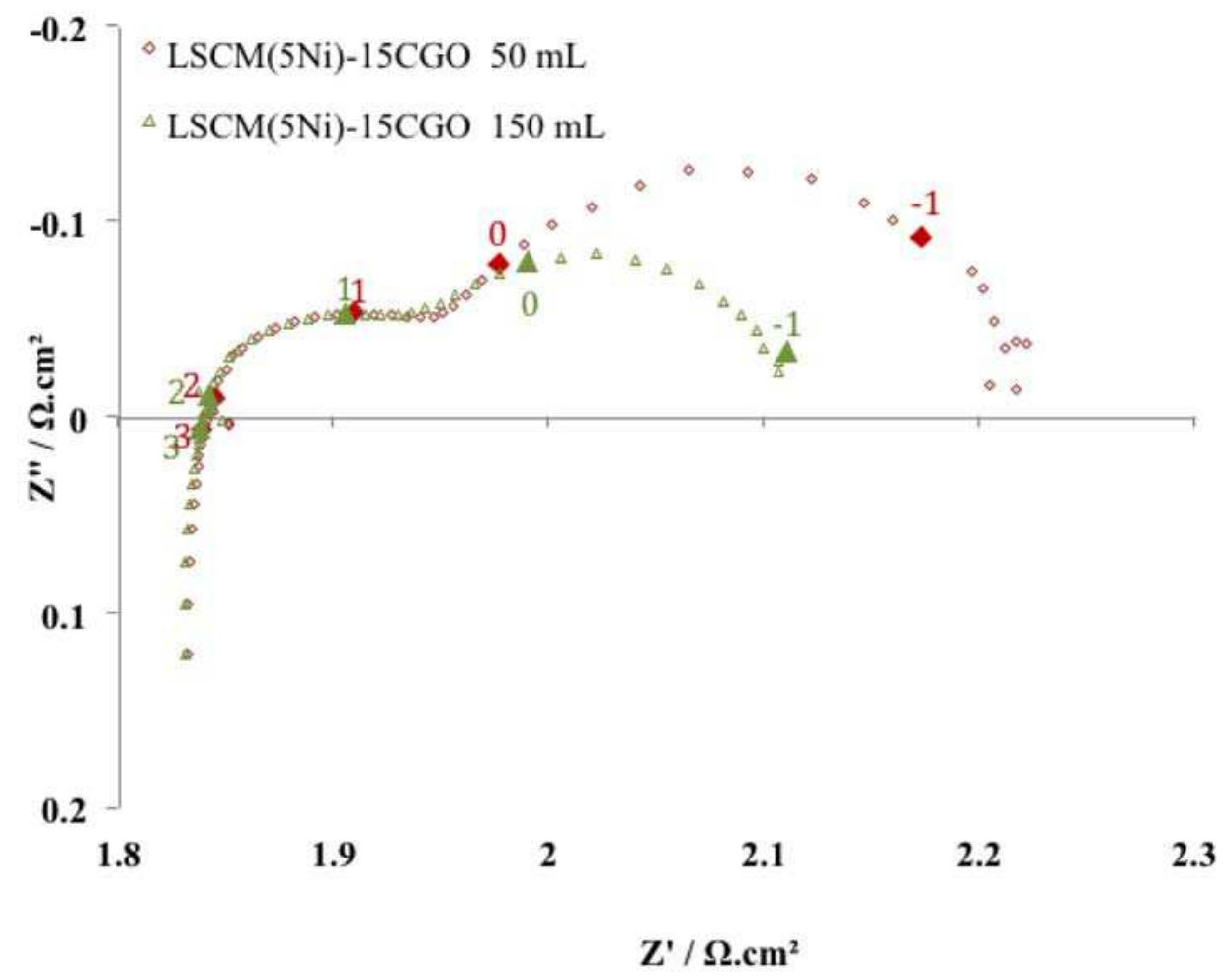

Figure 4. Impedance diagrams recorded at open circuit voltage for $\operatorname{LSCM}(5 \mathrm{Ni})-15 \mathrm{CGO}$ material composition with an anode gas flow rate of $50 \mathrm{~mL} / \mathrm{min}(\diamond)$ and $150 \mathrm{~mL} / \mathrm{min}(\Delta)$. $\mathrm{T}=900^{\circ} \mathrm{C}$, anode gas composed of $97 \% \mathrm{H}_{2}+3 \% \mathrm{H}_{2} \mathrm{O}$.

Effect of the Working Temperature on the EIS Response. According to Figures 5 and 6 , increasing the temperature leads to a very important decrease in the impedance at the whole frequency range, which means that all the main electrochemical mechanisms governing the anode reaction are thermally activated. This decrease is more important for the LSCM-15CGO composition (Figure 5) for which $\mathrm{R}_{\mathrm{p}}$ evolves from $6.23 \Omega$ at $700^{\circ} \mathrm{C}$ to 
$1.43 \Omega$ at $800^{\circ} \mathrm{C}$ and $0.47 \Omega$ at $900^{\circ} \mathrm{C}$. However, the influence of temperature on the cell behavior is different depending on the material composition. Indeed, for LSCM-15CGO, there is an impedance contribution in the $10 \mathrm{kHz}-100 \mathrm{~Hz}$ frequency range, clearly present at $700^{\circ} \mathrm{C}$, that decreases at $800^{\circ} \mathrm{C}$ to finally disappearing at $900^{\circ} \mathrm{C}$ (Figure 5). The same trend is observed for LSCM (not shown here). This impedance contribution is also present for $\operatorname{LSCM}(5 \mathrm{Ni})-15 \mathrm{CGO}$ at $700^{\circ} \mathrm{C}$ but already disappears at $800^{\circ} \mathrm{C}$ (Figure 6), revealing that the $\operatorname{LSCM}(5 \mathrm{Ni})-15 \mathrm{CGO}$ composition allows a more optimized cell behavior for a lower working temperature.

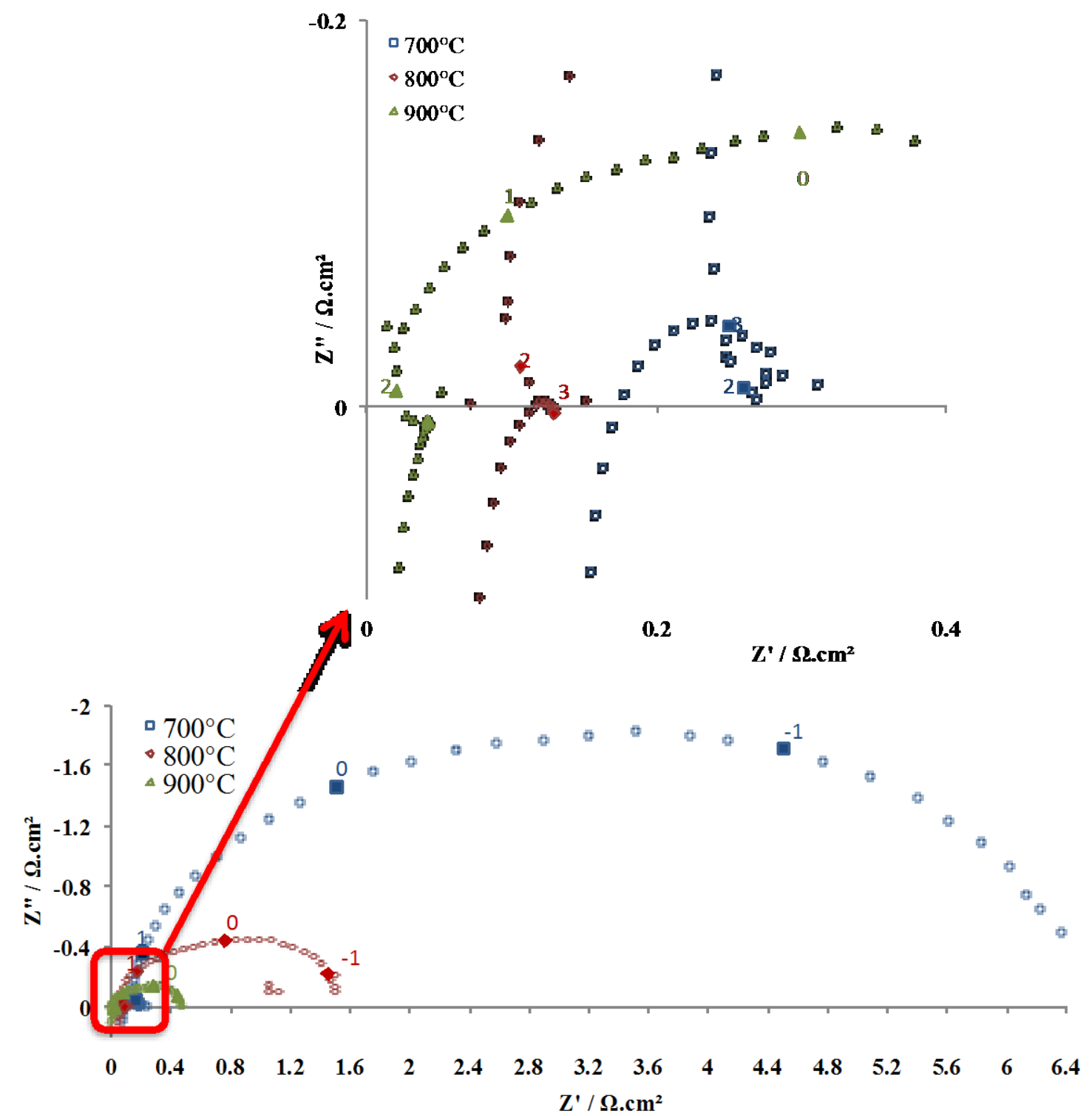

Figure 5. Impedance diagrams recorded at open circuit voltage for LSCM-15CGO (same as LSCM) with an anode gas flow rate of $150 \mathrm{~mL} / \mathrm{min}$. Anode gas composed of $97 \% \mathrm{H}_{2}$ $+3 \% \mathrm{H}_{2} \mathrm{O} . \mathrm{T}=900^{\circ} \mathrm{C}(\Delta), \mathrm{T}=800^{\circ} \mathrm{C}(\diamond)$ and $\mathrm{T}=700^{\circ} \mathrm{C}(\square)$. 


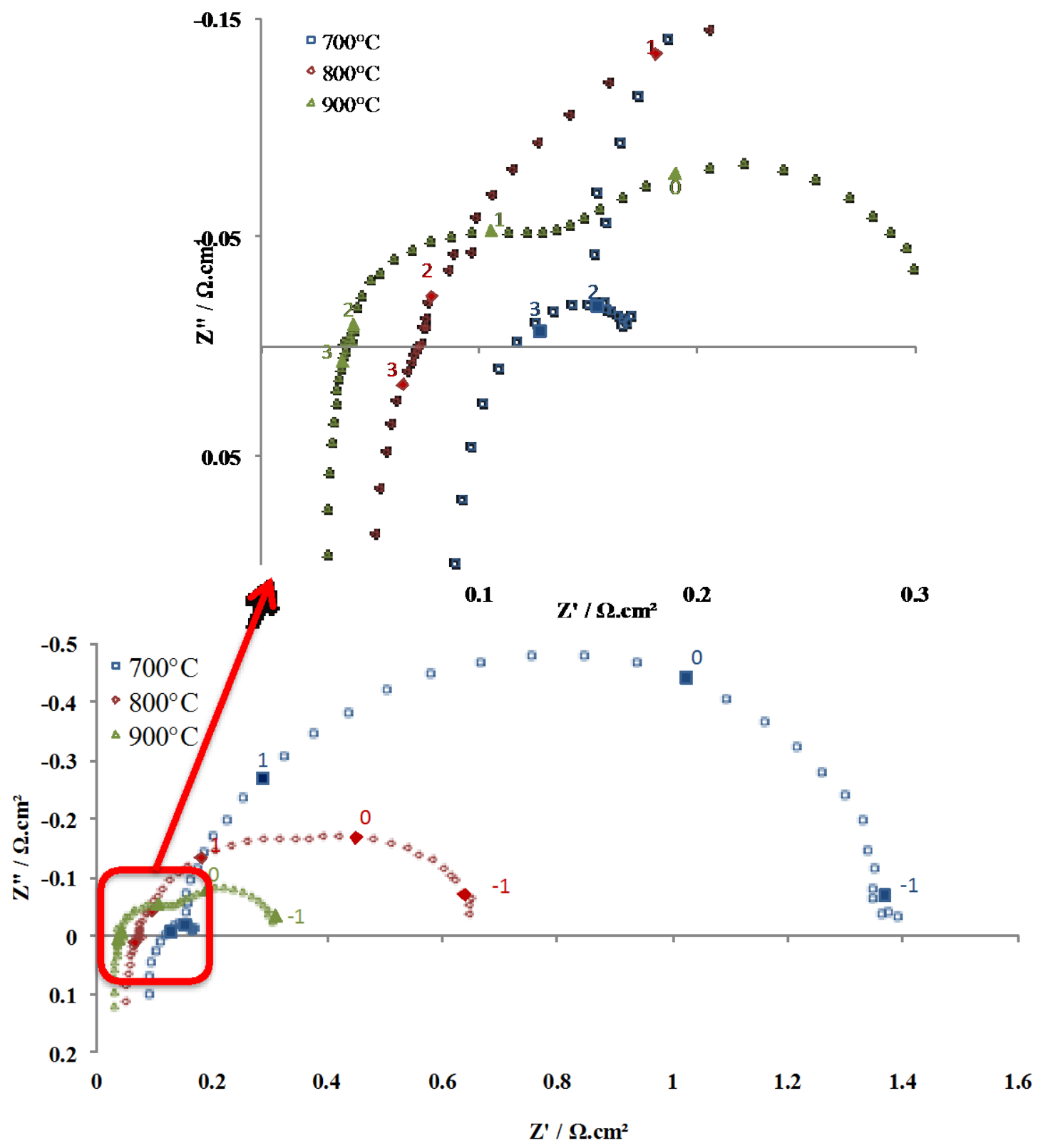

Figure 6. Impedance diagrams recorded at open circuit voltage for LSCM(5Ni)-15CGO with an anode gas flow rate of $150 \mathrm{~mL} / \mathrm{min}$. Anode gas composed of $97 \% \mathrm{H}_{2}+3 \% \mathrm{H}_{2} \mathrm{O}$. $\mathrm{T}=900^{\circ} \mathrm{C}(\Delta), \mathrm{T}=800^{\circ} \mathrm{C}(\diamond)$ and $\mathrm{T}=700^{\circ} \mathrm{C}(\square)$.

\section{Conclusion}

Lower values of the polarization resistance were measured for the samples containing CGO compared to pure LSCM ones. This was characterized by a decrease of the impedance in the frequency range from $100 \mathrm{~Hz}$ to $10 \mathrm{~Hz}$, likely due to the higher ionic conductivity brought by the addition of CGO. The addition of $5 \mathrm{wt} \%$ of submicron $\mathrm{Ni}$ to LSCM-CGO led to a remarkable decrease in $\mathrm{R}_{\mathrm{p}}$. This effect was even more pronounced for the samples containing $5 \mathrm{wt} \%$ of exsoluted $\mathrm{Ni}$ nanoparticles, characterized by a decrease of the impedance in the whole frequency range, and especially from $100 \mathrm{~Hz}$ to $1 \mathrm{~Hz}$, suggesting an enhancement of the electrochemical 
processes related to anode charge transfer. Increasing the gas flow rate results mainly in a significant decrease in the impedance from $1 \mathrm{~Hz}$ to $0.01 \mathrm{~Hz}$, likely to be related to gas diffusion phenomena. All the main electrochemical mechanisms governing the anode reaction were thermally activated. This was less pronounced in the presence of $\mathrm{Ni}$ exsoluted nanoparticles.

\section{References}

1. Y. H. Huang, R. I. Dass, Z. L. Xing, J. B. Goodenough, Science, 312 (5771), 254 (2006).

2. A. D. Aljaberi, J. T. S. Irvine - J. Mat. Chem. A, 1, 5868 (2013).

3. D. Neagu, G. Tsekouras, D.N. Miller, H. Menard, J. T. S. Irvine, Nature Chemistry, 5, 916 (2013).

4. G. Tsekouras, D. Neagu, J. T. S. Irvine, Energy Environ. Sci., 6, 256 (2013).

5. S. Tao, J.T.S. Irvine, Nature Materials, 2, 320 (2003).

6. S. Boulfrad, M. Cassidy, E. Djurado, J. T. S. Irvine and G. Jabbour, Int. J. Hydrogen Energy, 38 (22), 9519 (2013).

7. S. Boulfrad, M. Cassidy, E. Traversa, J. T. S. Irvine, ECS Trans, 57 (1), 1211 (2013).

8. S. Boulfrad, M. Cassidy, J. T. S. Irvine, Solid State Ionics 197, 37 (2011).

9. Q. Ma, B. Iwanschitz, E. Dashjav, S. Baumann, D. Sebold, I. Arul Raj, A. Mai, F. Tietz, J. Power Sources, 279, 678 (2015).

10. D. Montinaro, A. R. Contino, A. Dellai, and M. Rolland, Int. J. Hydrogen Energy, 39, 21638 (2014).

11. M. J. Jørgensen and M. Mogensen, J. Electrochemical Soc, 148 (5), A433 (2001). 